\title{
Immunizing Neoantigen Peptide Antibody
}

National Cancer Institute

\section{Source}

National Cancer Institute. Immunizing Neoantigen Peptide Antibody. NCI Thesaurus.

Code $C 126418$.

Any antibody that recognizes tumor-associated peptide antigens that are in neoantigen peptide-based vaccines. 